\title{
Nuclei of Taxus baccata: Flavanols Linked to Chromatin Remodeling Factors
}

\author{
Walter Feucht, ${ }^{1}$ Heike Dithmar, ${ }^{2}$ and Jürgen Polster ${ }^{2}$ \\ ${ }^{1}$ Department für Pflanzenwissenschaften, Technische Universität München (TUM), \\ Wissenschaftszentrum Weihenstephan (WZW), 85354 Freising, Germany \\ ${ }^{2}$ Department für Biowissenschaftliche Grundlagen, Fachgebiet für Physikalische Biochemie, \\ Technische Universität München (TUM), Wissenschaftszentrum Weihenstephan (WZW), 85354 Freising, Germany \\ Correspondence should be addressed to Jürgen Polster, j.polster@wzw.tum.de
}

Received 2 March 2009; Revised 9 July 2009; Accepted 14 September 2009

Recommended by Jutta Ludwig-Mueller

\begin{abstract}
Microscopic studies of young needles and shoot tips from Taxus baccata showed that flavanols are localized in the nuclei. This observation is based on the histochemical staining of flavanols with the DMACA reagent. The colour that is obtained with this reagent varies from pale to deep blue, depending on the amount of flavanols. This study is focused on nondifferentiated cell lineages and on differentiating cells. The key point to note is that all nuclei of a cell lineage showed a uniform DMACA staining pattern based on the amount and structural appearence of nuclear flavanols. This points to transcriptional and epigenetic programming. However, comparing various cell lineages from different shoot tips and needles revealed a lineage-specific expression of nuclear flavanols. This result implied that both positional and developmental signals from neighbouring cells were involved in the nuclear flavanol binding of lineages. The cells of a developmentally advanced lineage loose their intimate contact and, then, they separate from each other to undergo an autonomous, individual sequence of differentiation. This in turn was accompanied by differences in the nuclear flavanol patterns of the single cells. Investigating different mitotic stages revealed a wide spectrum in flavanol staining intensities of the chromosomes. These observations should be linked to UV-VIS spectroscopical kinetic results indicating that nuclear flavanols bound to histones are involved in epigenetically regulated modification of chromatin. The kinetic studies show that catechin is relatively rapidly degraded by oxygen in the presence of $\mathrm{Mg}^{2+}$-ions. However, this degradation reaction is strongly inhibited when histone proteins were added. This behaviour is a clear indication that coregulatory interactions exist between catechin and histones.
\end{abstract}

Copyright () 2009 Walter Feucht et al. This is an open access article distributed under the Creative Commons Attribution License, which permits unrestricted use, distribution, and reproduction in any medium, provided the original work is properly cited.

\section{Introduction}

Trees of Taxus baccata are rich in flavonoids and make use of them as defense compounds against pathogens (Kim et al. [1]). A special subgroup of flavonoids are the flavanols. In previous studies it was shown that commercial histones have the potential to associate with flavanols (Polster et al. [2], Feucht et al. [3]). It is assumed that Taxus histones also bind to flavanols. With the aid of microlaser dissection techniques and UV visible spectroscopic titration, it could be established that flavanols are genuinely present in conifer nuclei (Polster et al. [4]). This agrees with a recent communication that starter enzymes of the flavonoid pathway, that is, chalcone synthases, were found to be located in nuclei of Arabidopsis
(Saslowsky et al. [5]). Hutzler et al. [6] previously also detected yellow fluorescing flavonoids in nuclei using microscopy .

Clearly the role and effects of flavonoids in nuclei have yet to be established. It is commonly accepted that the phenolic catechol group as a reducing agent is implicated in repair of oxidized DNA (Saran et al. [7]). However, it should not be overlooked that there is a complicated interplay between oxidant and antioxidant signaling (Foyer and Noctor [8]). Importantly, a continual exchange of photosynthetic redox signals exists under many environmental conditions between the nucleus and the chloroplasts (Fey et al. [9]). These redox signals control nuclear gene expression (Fey et al. [9]). Therefore, flavanols deserve special attention in this 
respect, as they easily undergo redox reactions. In a wider context, plant polyphenols could be involved in protecting the stability of the human genome (Ferguson [10]).

In previous studies (Feucht et al. [11], and literature cited therein) it became evident that the nuclei of a number of plant species frequently stained with different intensities form flavanols ranging from pale to dark blue with the well-established DMACA ( $p$-dimethylaminocinnamaldehyde) reagent. The aim of this study was to find possible reasons of such a diversity and therefore, two distinct cell types from young needles and shoot tips were studied: (1) multipotent lineage cells and (2) single cells which enter into a differentiation program.

Cell lineages of shoot tips originate from apical shoot meristems as derivatives from stem cells (Lyndon [12], Marenduzzo et al. [13]). The cell lineages of leaflets then become established by communication between stem cells and their neighbouring cells at the flanks of the apical meristem (Lenhard and Laux [14]). Independent of the origin of the lineages, their cells characteristically share a number of common physiological processes (Mauseth [15]). However, specialized cells as derivatives from a prior lineage are functionally distinct units, setting into motion changes in size, shape, and physiology.

Catechins themselves pose a great physiological problem for the nucleus since it is well known that they oxidize relatively rapidly. Thus, strategies had to be developed by the nucleus to prevent completely any oxidative degradation. Histone proteins may play a possible role by forming association complexes with catechins. A reduction of catechin degradation by these complexes is demonstrated using UVVIS spectroscopic kinetic methods.

\section{Materials and Methods}

2.1. Materials. The present investigation is based on long term studies performed from 2001 to 2007. Seven trees of Taxus baccata (English jew), between 10 and 25 years old were used for sampling. The trees are located in the Botanical Garden of Weihenstephan, $30 \mathrm{~km}$ north of Munich. The site is characterized by a deep loamy soil and the trees studied are shaded by overstory trees. Young shoot tips and needles were collected from spring time to early summer. Preferently, meristematic cells were investigated and compared with maturing, single parenchyma cells. During the course of 7 years a total of 140 samples were collected from early April to late July. From each subsample about 300 cells were observed, thus a total of approximately 42,000 nuclei have been studied microscopically.

2.2. Methods. Fresh tissues were stained (i.e. prior embedding procedures were not employed) with the $p$ dimethylaminocinnamaldehyde reagent (1\% DMACA dissolved in $0.75 \mathrm{M}$ sulphuric acid). Prior to staining, young needles were halved along the main vein and shoot tips were sectioned once along the primary vascular bundle with a razor blade (only about $5 \%$ of the cells were visibly injured). After staining for 15 to 20 minutes the tissues were gently squashed with a microslide. It can be assumed that the sulphuric acid component of the reagent caused some histological damage of the middle lamella which resulted in a loosening of the cellular contact. As a consequence all differentiating cells became slightly separated and single cells became recognizable. However, the lineage cells were still connected to each other. By microscopy of defined needle sectors, it was possible to compare directly the nearest neighbour cells.

Phenolic histochemistry suffers from some inherent problems. Enlarging cells at a given distance back from the meristem frequently develop vacuoles that are filled with flavanols. However, leaching of flavanols as a consequence of the staining procedures could not be observed. It is possible that the cinnamic aldehyde moiety of the reagent operates in analogy with formaldehyde which forms insoluble condensation products with plant phenols (Matsuo [16]). Binding of tonoplast proteins with flavanols might also take place, because the very low $\mathrm{pH}$ of the DMACA reagent eventually results in sealing reactions (compaction).

The stained cells were visualized using a Zeissphotomicroscope (Axioscope). Scanning of the photomicrographs was performed with an equipment of Nikon Cool Scan IV E.D.

2.3. Chemicals for Kinetic Measurements. Histone proteins (from calf thymus) were purchased from BioCat (Heidelberg, Germany; product code: 1136-10-BV), (+)-catechin (puriss.; product code: 6200 ) and Tris $=$ Tris-(hydroxymethyl)amino methane (PUFFERAN, $\geq 99.9 \%$, p.a.) were obtained from Carl Roth (Karlsruhe, Germany), ethanol (for spectroscopy; "Uvasol") from Merck (Darmstadt, Germany), oxygen 4.5 (content $12 \mathrm{~L}$; "Minican"; 12 bar) and argon 5.0 (content 12 L, "Minican", 12 bar) from Linde (Unterschleißheim, Germany), hydrochloric acid (min. 25\%; puriss. p.a.) from Riedel-de Haën (Sigma Aldrich, Seelze, Germany) and magnesium chloride hexahydrate (AnalaR Normapur, 99.0102.0\%) from VWR (Leuven, Belgium).

2.4. Buffer and Solutions for Kinetic Measurements. A catechin stock solution was prepared by dissolving catechin in ethanol to give a concentration of $10 \mathrm{mg} / \mathrm{mL}(34.5 \mathrm{mM})$.

Buffer solutions: $0.1 \mathrm{M}$ Tris and $10 \mathrm{mM}$ magnesium chloride were prepared in $\mathrm{H}_{2} \mathrm{O}$, and the $\mathrm{pH}$ was adjusted to 8.0 with $\mathrm{HCl}$ ( $\mathrm{pH}$ meter: WTW inoLab $\mathrm{pH}$ Level1). $3.3 \%$ ethanol was added to the buffer and the mixture was gassed with oxygen for three minutes. Histone protein was carefully dissolved in the gassed ethanolic buffer solution to give a concentration of $2 \mathrm{mg} / \mathrm{mL}$. The experiment was repeated, however, in the absence of histone proteins; hereby, oxygen was either added or omitted (control) to the ethanolic buffer solutions. Additionally, a catechin solution in ethanolic buffer was gassed with argon and studied spectroscopically.

2.5. Kinetic Measurement of Catechin Degradation. $500 \mu \mathrm{L}$ of ethanolic buffer protein solution was placed into a quartz cuvette $(1 \mathrm{~cm}$ pathlength, total volume $600 \mu \mathrm{L})$ and the cuvette was kept at $20.0^{\circ} \mathrm{C}$ for 5 minutes. Then, kinetic 
measurement was started after addition of $10 \mu \mathrm{L}$ catechin stock solution. Reaction spectra were recorded with a diode array spectrometer (Hewlett Packard model 8453, Agilent Technologies GmbH, Waldbronn, Germany). Kinetics were observed for 15 hours (parameters of kinetic measurement: integration time $0.1 \mathrm{~s}$, run time $54000 \mathrm{~s}$, cycle time $600 \mathrm{~s}$, increment cycle time: $2 \%$ after $7200 \mathrm{~s}$ ). Approximately 60 spectra were recorded in each run. Time dependent curves were plotted for the wavelength of $434 \mathrm{~nm}$ (see Figure 3, curve c: with histones).

In analogy, the degradation of catechin was also studied in the corresponding ethanolic buffer solution, however in the absence of histones. Hereby, the solution was gassed additionally with oxygen (see Figure 2 and Figure 3, curve a) and, as a control, without additional gassing (see Figure 3, curve b).

A drop of cuvette content was placed onto the top of an electrode of an oxygen gauge after kinetic measurement for determining roughly semiquantitatively the oxygen content (Voltcraft DO-100; measurement range 0-20 mg/L; accuracy $\pm 0.4 \mathrm{mg} / \mathrm{L}$ at $\left.23 \pm 5^{\circ} \mathrm{C}\right)$.

\section{Results}

Figures 1(a)-1(k) show three characteristic categories of developmental cell stages. Figures 1(a)-1(d) (shoot tips) show the range from extremely pale to extremely dark flavanol staining which is typical for Taxus. Figures 1(d)1 (g) represent typical lineages of both needles and shoot tips. Finally, Figures $1(\mathrm{~h})-1(\mathrm{k})$ illustrate characteristic single meristematic cells derived from lineages (except upper row of Figure $1(\mathrm{~h})$ ). The nuclear flavanol staining shown in Figure 1 is a representative for the growth period from early April to late July. During the winter rest period, the nuclear flavanol staining was always very pale to zero. There was no significant variation in the staining pattern during the seven years of investigation (except the very dry period during spring 2007 when the flavanols disappeared almost completely from the nuclei). Also, the age of the investigated trees (10 to 25 years) did not affect visibly the staining pattern.

3.1. Taxus Shoot Tips (Figures $1(a)-1(d)$ ). Most cells from emerging, actively growing shoot tips are small sized and exhibit a high nuclear-cytoplasmic ratio. For example, the centrally located interphase nucleus (Figure $1(\mathrm{a}) *$ ) has a diameter of $8 \mu \mathrm{m}$ and the rounded cell measures $10 \mu \mathrm{m}$ in diameter (both, the cytoplasm and the thin primary cell wall do not stain for flavanols). The flavanols of the dark blue staining nucleus (Figure 1(a)) can be distinguished between lighter coloured euchromatin and dense blue spots of compacted heterochromatin. In contrast, the adjacent nucleus (Figure $1(\mathrm{a})$, left $<$ ) exhibits a rather pale blue euchromatin with a prominent almost colourless nucleolus, which has virtually no flavanols. Some faint flavanol blobs can be observed around the nucleolus. A dividing cell shows lightly stained metaphase chromosomes of a thread-like appearance (Figure 1(a), below). Some faint foci of slightly more intense flavanol staining can be seen along the mitotic spindle.
The development of vacuoles depends very much on the cell size. In the meristematic shoot tips, there are only a few specialized and enlarged cells that store abundant flavanols in vacuoles (Figure 1(b), left, one large and one small vacuoles). The large, reniform and dark blue vacuole surrounds half of the comparatively pale nucleus $(* 7 \mu \mathrm{m}$ in diameter). However, the two neighbouring cells are without vacuoles (Figure 1(b), right). They show large nuclei, measuring about $11 \mu \mathrm{m}$ in diameter and display a prominent blue, somewhat diffuse flavanol pattern. It should be noted that all three nuclei (Figure 1(b)) lack dense flavanol granules.

Figure 1(c) (upper row) shows two enlarged, adjacent cells which appear much the same in appearance regarding size and shape. Both cells appear to be structurally synchronized as multivacuolate cells that contain abundant flavanols. These highly specialized cells can frequently be found closely aligned to sieve tubes. Both centrally located, sharply defined nuclei are compacted to a hypercondensed state (only around 6 to $7 \mu \mathrm{m}$ in diameter), with many dark blue spots typical of condensed heterochromatin being interspersed in euchromatin.

Quite different in development are the two adjacent vacuole-free cells with a large nucleus each (Figure 1(c), lower row). Both rather loosely structured, less coloured nuclei are about 12 to $13 \mu \mathrm{m}$ in length. Because of their large size they are assumed to be in prophase. Some fine blobs or short threads of condensed chromatin are dispersed over the euchromatin. Also the cytoplasm of both cells is covered with a pale film of flavanols.

Meristematic cells are capable of undergoing some unidirectional, successive divisions resulting in the formation of cell lineages. The cells of these lineages have a particular tight contact with each other that is caused by adhesion molecules of the extracellular matrix. Comparing both coaligned fourcelled lineages (Figure 1(d)), it is evident that the nuclei of the upper row (only three cells are shown) stained a lighter blue than those of the lower row. Condensed appearance of nuclear flavanol spots is also more pronounced in the lower row, while there are finer grained spots in the upper row. Although the average cell areas of both lineages appear to be similar, the more rectangular shape of two cells of the lower row suggests that cytokinesis had occurred recently.

3.2. Taxus Needles (Figures 1(e)-1(k)). The four-celled line-age with extremely blue nuclei is most informative (Figure 1(e)). The diffuse euchromatin is overlaid by extreme blue patches of heterochromatin clumps covering about three-quarters of the nuclear surface. Even the cytoplasm around the nuclei stains unusually blue. Three adjacent parenchyma cells are densely packed with starch granules (Figure 1(e), S) and show lower levels of nuclear flavanols than those nuclei of the adjacent lineage.

A further four-celled lineage (Figure 1(f), left, only two cells are shown) displays nuclei with a high content of flavanols, similar to those shown in Figure 1(e), but without compacted patches. The flavanols in both nuclei and cytoplasm appear slightly more diffuse.

The more elongated cells of the adjoining four-celled lineage display only a moderate nuclear flavanol association 


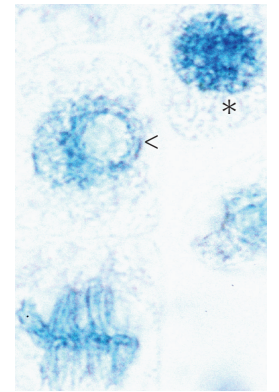

(a)

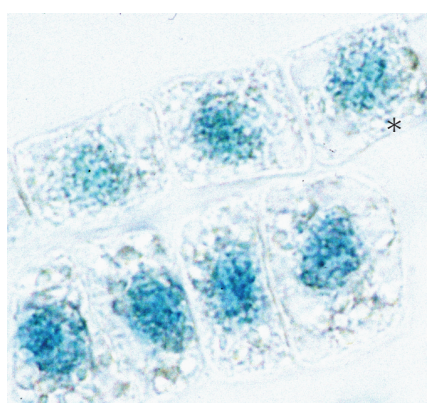

(d)

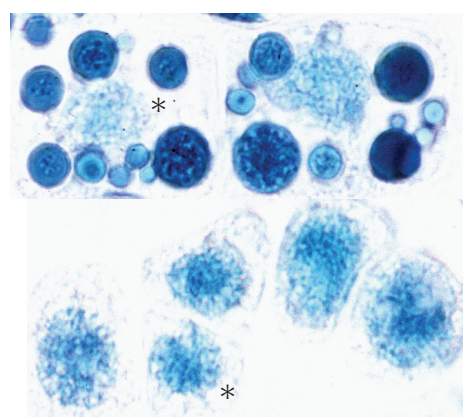

(h)

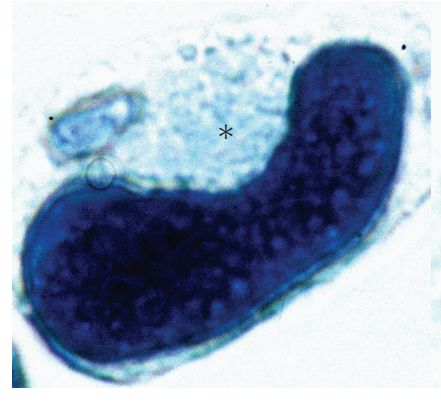

(b)

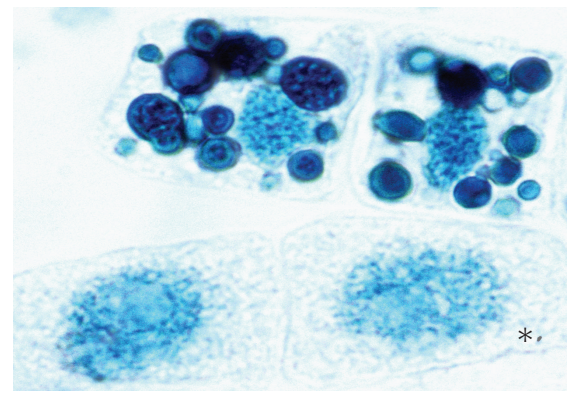

(c)

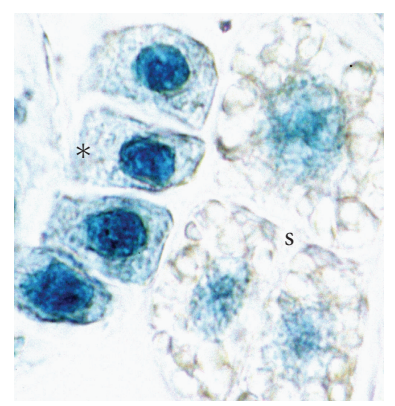

(e)

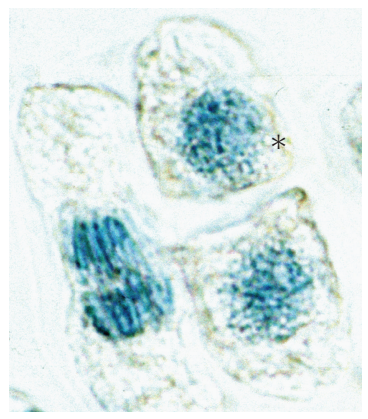

(i)

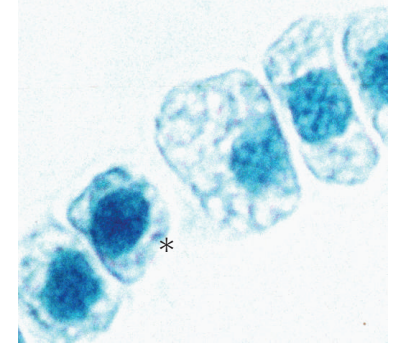

(f)

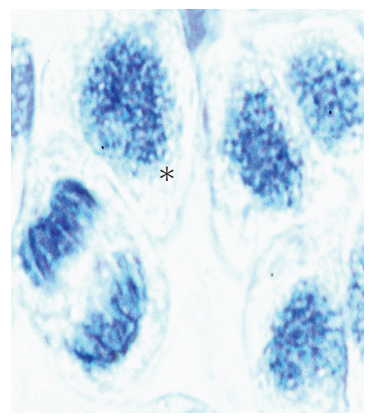

(j)

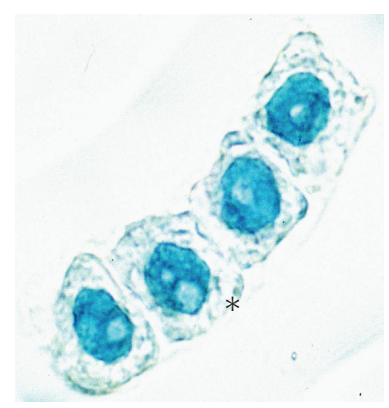

(g)

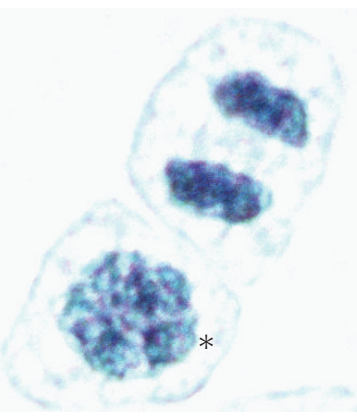

(k)

Figure 1: Nuclear flavanol patterns as evidenced by blue colouration with the selective DMACA reagent. ( ${ }^{*}$ Size of the nuclei in $\mu$ m diameter). Elongating shoot tips (a)-(d). (a) Dark blue interphase cell (nucleus* $8 \mu \mathrm{m}$ in diameter). Pale blue nucleus with a large nucleolus $(<$ ) and pale chromosome staining during metaphase. (b) Mature cell from the phloem region showing a large kidney-like vacuole filled with flavanols. The halfway enclosed nucleus $\left({ }^{*} 7 \mu \mathrm{m}\right.$ in diameter) stains only a moderate blue. Two nearby located nuclei of vacuole-free cells (nucleus* $11 \mu \mathrm{m}$ in diameter) stained a comparatively darker blue (see right side of (b)). (c) Two multi-vacuolate cells having achieved large quantities of stored flavanols. The nuclei are compacted ( ${ }^{*} 6 \mu \mathrm{m}$ in diameter), and stain a very deep blue colour together with fine granules of condensed chromatin. Two adjacent cells without vacuoles possess enlarged and moderate blue nuclei (*about 12 to $13 \mu \mathrm{m}$ in length). Condensed chromatin spots are fine structured. The size of the nuclei points to a prophase stage. (d) Two adjacent lineages exhibit a slightly unequal size and show a different nuclear flavanol pattern (nucleus $8 \mu \mathrm{m}$ in diameter). Upper lineage: pale blue nuclei with finer grained chromatin spots. Lower lineage: moderate blue nuclei with coarse grained chromatin spots. Elongating needles (e)-(k). (e) cells with distinct nuclear flavanol aggregation patterns. The nuclei of the lineage cells stain dark blue $(* 7 \mu \mathrm{m}$ in diameter) which stand out in sharp contrast against the lighter blue cytoplasm. Patches of dark blue heterochromatin indicate a special nuclear condition. The nuclei of the starch cells $(s)$ stain pale blue. (f) Members of two cell lineages consist of four cells each, but only two cells are shown. Size, shape, and nuclear staining patterns differ markedly. The small lineage cells indicate more nuclear flavanol deposition (nucleus* $7 \mu \mathrm{m}$ in diameter), compared with the large lineage cells. (g) this cell lineage is characterized by nuclei which are almost the same in size and shape. The nuclear flavanol pattern is generally smooth, lacking dense chromatin spots (nucleus* $8 \mu \mathrm{m}$ in diameter). Strikingly, each nucleus has a small nucleolus. (h) two multivacuolate parenchyma cells each stores abundant flavanols. Their centrally located nuclei are less coloured than those of the adjacent five vacuole free cells (nucleus* $7 \mu \mathrm{m}$ in diameter). The five single cells are derivatives from a former lineage and have started to differentiate in size, shape, and nuclear flavanol pattern. (i) elongated cell with anaphase chromosomes and two daughter cells resulting from a recent transversal division (nucleus* $8 \mu \mathrm{m}$ in diameter). Distinct chromosomal and nuclear domains stain a dark blue. (j) ana-telophase chromosomes and four interphase cells with dark blue nuclei. Somewhat diffuse but marked spots of heterochromatin are distributed throughout the euchromatin (nucleus*10 $\mu \mathrm{m}$ in length). (k) very compacted, somewhat diffuse chromatin during mid-telophase. The nucleus of the interphase cell is slightly diffuse and of a deep colour $(* 8 \mu \mathrm{m}$ in diameter) together with some large heterochromatin patches. 


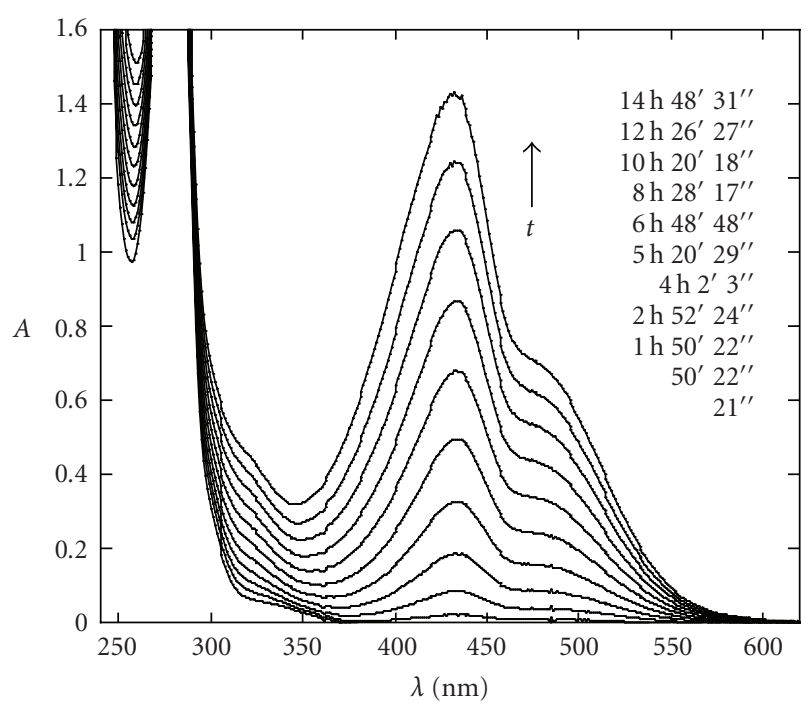

Figure 2: Reaction spectra. Stability of catechin in $0.1 \mathrm{M}$ Tris buffer $\left(\mathrm{pH} 8.0,20.0^{\circ} \mathrm{C}\right)$ containing $10 \mathrm{mM} \mathrm{MgCl}_{2}$ gassed with oxygen.

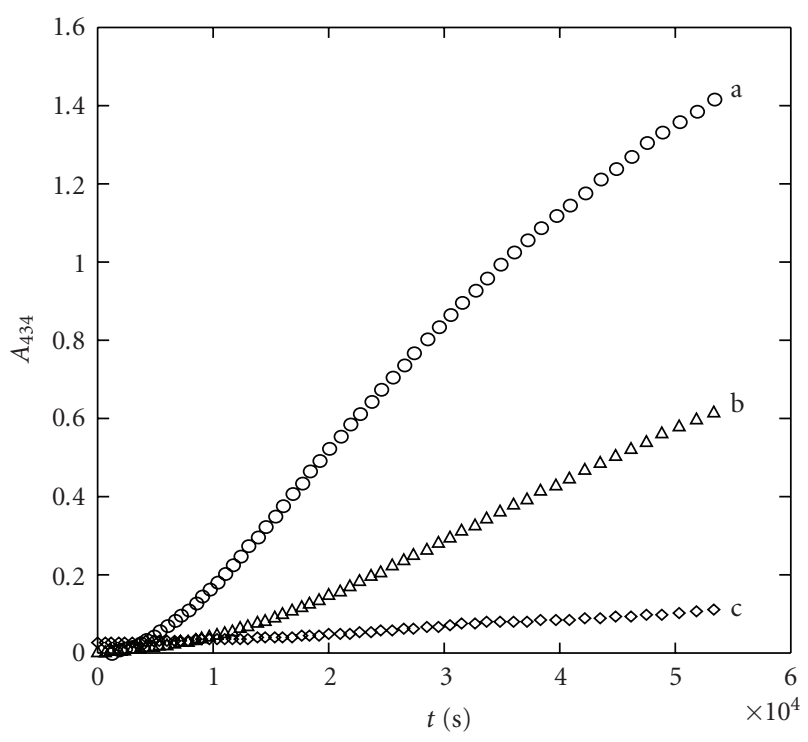

Figure 3: Absorbance time curves of different reaction conditions for the degradation behaviour of catechin: (a) absorbance time curve of spectra shown in Figure 2 (solution gassed with oxygen), (b) stability of catechin in $0.1 \mathrm{M}$ Tris buffer $\left(\mathrm{pH} 8.0,20.0^{\circ} \mathrm{C}\right)$ containing $10 \mathrm{mM} \mathrm{MgCl}_{2}$ without additional gassing with oxygen, (c) stability of catechin in the presence of histone proteins $(2 \mathrm{mg} / \mathrm{mL})$ in $0.1 \mathrm{M}$ Tris buffer $\left(\mathrm{pH} 8.0,20.0^{\circ} \mathrm{C}\right)$ containing $10 \mathrm{mM}$ $\mathrm{MgCl}_{2}$ gassed with oxygen.

(Figure 1(f), right, only two complete cells are shown). Prominent blobs of condensed chromatin are dispersed over the lighter blue euchromatin, while the cytoplasm showed somewhat curved flavanol aggregates.

Figure 1(g) reveals an impressive example of a fourcelled lineage packet which acts as a morphological and physiological unit. All four cells and their nuclei are as similar as four "eggs" with regard to size and shape. All four nuclei display a pronounced smooth appearance of chromatin, without any dense chromatin spots. Strikingly, the presence of small-sized, similar looking nucleoli in each lineage cell points to a strict developmental synchrony.

As in shoot tips, needles also contain highly differentiated, stationary phase cells with many sharply defined storage vacuoles that are filled with flavanols (Figure 1(h), upper row). It is evident that the nuclei of the two adjacent multivacuolate cells differ both in size and flavanol density. However, they lack prominent chromatin spots, in contrast to the ones observed in the shoot tips (Figure 1(c)).

In the same Figure $1(\mathrm{~h})$ (below), five cells probably derived from a former lineage begin to develop autonomously in an individual way as they vary markedly in size, shape, and flavanol aggregation.

In the phloem, some stretched cells can be observed (Figure 1(i), left); they divide only occasionally. It is important to note that most of the anaphase chromosomes stain a deep, somewhat greyish blue for flavanols. The two coaligned cells resulted from recent cell division and are rather similar in shape and size (Figure 1(i) nucleus* $8 \mu \mathrm{m}$ in diameter). Coarse-grained chromatin structures are prominent in both daughter cells (Figure 1(i)).

Comparison of the anaphase (Figure 1(i)) with the anaphase-telophase stage (Figure $1(j)$, left) reveals quite a different picture. A blue diffuseness around the dark staining chromosomes is obvious. The adjacent four interphase nuclei ( ${ }^{*} 10 \mu \mathrm{m}$ in length) differ somewhat in size and show a varying DMACA flavanol reaction. Also irregularly dispersed chromatin spots show some cell to cell variations.

At late-telophase (Figure $1(\mathrm{k})$ ), the newly forming haploid daughter nuclei are quite identical in both density and diffuse appearance of flavanols. The condensed chromatin blobs are also somewhat diffuse. The nearby located circular interphase nucleus $(* 8 \mu \mathrm{m}$ in diameter) exhibits likewise a diffuse chromatin pattern with a few more distinct and condensed blue subnuclear regions.

3.3. Stability of Catechin: A UV-VIS Spectroscopic Investigation. It was shown that association equilibria can found UVVIS spectroscopically between catechin and histone sulphate containing the histones $\mathrm{H} 1, \mathrm{H} 2 \mathrm{~A}, \mathrm{H} 2 \mathrm{~B}, \mathrm{H} 3$, and $\mathrm{H} 4$ (Polster et al. [2]). However, the association behaviour seems to be dependent on the histone batch purchased. When, for example, another isolation product of histone proteins is used, no interactions were observed spectroscopically with catechin under the same titration procedures $(0.1 \mathrm{M}$ Tris buffer, pH 8.0) (Feucht et al. [11]). Different epigenetic patterns of the histone proteins might be an explanation for these conflicting results.

$\mathrm{Mg}^{2+}$ plays an important role in condensing chromatin and its concentration increases in mammalian nuclei at interphase from $3.0 \mathrm{mM}$ to $17 \mathrm{mM}$ in chromosomes at metaphase (Tremethick [17], Strick et al. [18]). Because of the relatively high $\mathrm{Mg}^{2+}$ concentrations in nuclei, the question arose whether $\mathrm{Mg}^{2+}$ may influence thermodynamic and kinetic properties of a solution containing catechin 
and histones. The histone batch, which showed no UVVIS spectroscopic interactions between catechin and histone proteins (Feucht et al. [11]), seemed to be here of special interest.

Catechin is chemically unstable when added to a $\mathrm{MgCl}_{2}$ Tris buffer solution $\left(0.1 \mathrm{M} ; \mathrm{pH} 8.0 ; 10 \mathrm{mM} \mathrm{MgCl}_{2} ; 20.0^{\circ} \mathrm{C}\right)$ which was aerated beforehand with pure oxygen for 3 minutes (see UV-VIS reaction spectra of Figure 2). The absorption change near $434 \mathrm{~nm}$ is particularly pronounced. The absorbance time $\left(\mathrm{A}_{\lambda}-t\right)$ diagram at $434 \mathrm{~nm}$ is shown in Figure 3, a. The lag phase at the beginning of the reaction curve is conspicuous. When no additional pure oxygen gassing is carried out, catechin is degraded more slowly as shown in Figure 3, b (the oxygen content of the $\mathrm{MgCl}_{2}$ Tris buffer was roughly one fourth less compared to that in Figure 3, a (at the "end" of reaction). Again, a pronounced lag phase can be observed at the beginning of the reaction.

The reaction behaviour is completely changed when a histone mixture (with $\mathrm{H} 1, \mathrm{H} 2 \mathrm{~A}, \mathrm{H} 2 \mathrm{~B}, \mathrm{H} 3$, and $\mathrm{H} 4$ ) is present in the $0.1 \mathrm{M}$ Tris buffer $(\mathrm{pH} 8.0)$ containing $10 \mathrm{mM} \mathrm{MgCl}$. As shown in Figure 3, c, the degradation is minimal during the first 15 hours even if the solution was aerated beforehand with pure oxygen. Nearly the same curve is obtained when the $\mathrm{MgCl}_{2}$-Tris buffer is not aerated with additional pure oxygen (curve in Figure 3 not shown). Accordingly, histone proteins can effectively protect catechin from oxygen degradation under the conditions investigated.

\section{Discussion}

4.1. Case Studies of Cell Lineages. Cell rows or lineages of Taxus contain a maximum of eight cells, but most consist of four cells which are firmly connected to each other by middle lamella and plasmodesmata (Figures 1(c), 1(d), 1(e), 1(f), 1(g)). This contact allows a steady exchange of signals and hormones within a lineage. A shoot tip lineage originates from stem cells of the shoot apex. Leaf lineages are induced by signaling molecules moving from the centre of a shoot apex into the lateral cell layers of the apical dome which form leaf primordia (Lenhard and Laux [14]). A lineage can divide for a short time to form up to eight derivatives. As outlined by Mauseth [15], a packet of a recently formed cell lineage can act as a physiological unit. Evidently, the members of a given cell lineage are strictly integrated into a common pattern of gene expression and metabolic cell status (Leyser and Day [19]). This is caused by mutual cell to cell signaling through plasmodesmata (Veit [20]). Uniformity of a lineage-specific flavanol expression indicates that the nuclear flavanols are subject to a chromatinmediated control. This implies that a Taxus lineage retained much of the stem cell characteristics- as previously stated by Singh and Bhalla [21] for plants.

As outlined by Marenduzzo et al. [13], the synchronization of a cell lineage is the result of the same transcriptional information. Thus in the case of Taxus lineages, the uniform loading of the (four) nuclei with flavanols is the consequence of an identical histone modification (epigenetic histone code). This implies also that quantitatively the same amounts of flavanols were produced for each nucleus.

If two Taxus lineages, even when closely aligned (Figure 1(d)) have their own autonomous pattern of flavanol expression, it is evident that the inherited pattern of a lineage is modified by extrinsic signals from neighbouring differentiated cells (Weigel and Jürgens [22], Leyser and Day [19]).

Most impressive in this respect are the cell lineages in Figures $1(\mathrm{e})$ and $1(\mathrm{~g})$. In the first case (Figure 1(e)), the nuclei appear to be overloaded with flavanols (which can also be seen, to some extent, in the cytoplasm). It can also be seen that the heterochromatin is extremely dense and clumped in the centre of each of the four nuclei. Perhaps, such an unusual nuclear flavanol pattern reflects extremely highly modified transcription factors, which could possibly give rise to an epigenetically silenced state of gene repression. It has been reported that cells undergoing programmed cell death display similar structural nuclear abnormalities (Wredle et al. [23], Gunawardena et al. [24]). Hypercondensed chromatins bear the danger of defective chromosomal torsions (Mazumdar and Misteli [25]).

In the second case (Figure $1(\mathrm{~g})$ ), the moderate blue nuclear flavanol pattern appears to be more fluid. Strikingly, each of the four nuclei developed similar nucleolar areas of about $2 \mu \mathrm{m}$ in diameter. The lineage-based formation of nucleoli points to synchronized transcriptional activity. This fluid nucleoplasm may allow movement of chromosomes within nuclei (Misteli [26]) which in turn favors enforced gene expression accompanied with hyperacetylation and high transcriptional activity (Grewal and Moazed [27]).

4.2. Case Studies of Differentiating Single Cells. Cells making an exit from a cell lineage undergo various successive steps of differentiation which lead to specialized cell types. A high degree of differentiation is shown by two cells with vacuoles containing abundant flavanols (Figure 1c, shoot tip). This cell type is positioned about $500 \mu \mathrm{m}$ beneath the apex. Their relative small nuclei (about $6 \mu \mathrm{m}$ in diameter) display a dark blue colour with a number of condensed chromatin spots. Compactness of nuclei increases ionic strength, reduces chromatin mobility, and most of the DNA is silenced (Gasser [28]). It is tempting to speculate about the extent to which the transcriptional activity is repressed in these compacted nuclei (Figure $1(\mathrm{c})$ ), where the cells may attain simply a flavanol storage function.

A similar cell type is found in the needles (Figure 1(h), upper row) but the corresponding nuclei are more loosely structured, have less flavanols, and lack granules of heterochromatin. Such a varied pattern of nuclear flavanol expression in structurally similar cells (shoot tips and needles, Figure 1(c) and 1(h) is at first sight surprising. However, both needles and shoot tips show different structural and functional organization of their tissues. Sucrose as a primary carbohydrate is capable of stimulating synthesis of monomeric, dimeric, and trimeric flavanol structures (LuxEndrich et al. [29]). However, if sucrose is channeled excessively into starch formation, the metabolic flux into flavanols might be restricted resulting in poor flavanol staining of the 
nuclei (Figure 1(e), three cells right). Alternatively, as sugars can also modulate hormone signaling, they may therefore also influence the transcriptional control of plant genes (Rolland et al. [30]).

A conspicuous nucleus (Figure 1(a)) shows a loosened pale blue structure with some denser flavanol foci around the prominent nucleolus which hardly stains for flavanols (Figure $1(\mathrm{a}),<$ ). A possible reason for such a nuclear organization might be acetylation of histone proteins which seems to reduce the nuclear affinity for flavanols (Feucht et al. [11]). Acetylation has a remarkable potential to unfold chromatin, and under certain conditions it may reduce or even block the formation of higher-order heterochromatin structures (Kouzarides [31]). A high degree of acetylation is necessary for chromatin remodeling to attain a loosened structure which then allows good access to transcription factors (Fuchs et al. [32], Hsieh and Fischer [33]). Two separate observations are of interest in this context: epigallocatechin is one of the naturally occurring nuclear flavanols in conifers (Feucht et al. [34]), and it has been shown that it can stimulate in vitro the transcription of nuclear extracts from HeLa cells (Böhl et al. [35]).

The thread-like metaphase chromosomes (Figure 1(a)) indicate a comparatively low flavanol binding when compared with the other mitotic spreads (Figures 1(i), 1(j), $1(\mathrm{k})$ ). The chromosomes of (Figure 1(a)) contrast sharply with the dark blue anaphase chromosomes which are very condensed in distinct territories (Figure 1(i)). As outlined by Sharma and Sen [36] and Tremethick [17], heterochromatins are found in chromosomes throughout the cell cycle. The unusual flavanol packaging during anaphase (Figure 1(i)) might be attributed to stressful mitotic conditions causing, for example, a decrease in fluidity of nucleosomes. Largescale compaction of chromatin domains can be induced by distinct physiological situations at any one time (Tremethick [17]).

At late telophase the newly intermingling daughter chromosomes usually decondense. On a speculative note, it is perhaps for this reason that the flavanol pattern attains at least transiently a biophysical state of diffuseness (Figure $1(\mathrm{k})$ ). This might be a prerequisite for an intranuclear mobility that is necessary for the correct repositioning of the newly intermingling interphase chromosomes. In support of this, Misteli [26] advocated that a certain diffusional dynamic mobility of nuclear molecules is necessary.

4.3. Stability of Catechin. The monomeric catechins with a B-ring catechol group possess the ability to easily undergo autooxidation to colourless or yellow $o$-quinones. Access of oxygen to these catechins, if located in the nuclei, would generate unstable oxidation products.

The curves $\mathrm{a}$ and $\mathrm{b}$ of Figure 3 clearly show that the catechin degradation reaction is dependent on the oxygen concentration. As shown by Jiménez-Atiénzar et al. [37], the mechanism of catechin oxidation is complex and results in a product with maximum absorbance near $440 \mathrm{~nm}(0.01 \mathrm{M}$ phosphate buffer, $\mathrm{pH}$ 7.5), which indicates an $o$-quinoic catechin structure. A similar absorption behaviour near $440 \mathrm{~nm}$ was also found at pH 8.0 (0.1 M Tris buffer, Figure 2).
Thus, the oxidation reaction product may be an $o$-quinoic catechin.

This oxidative degradation of catechin is almost prevented in the presence of a sufficient amount of histone proteins even in the presence of a high oxygen concentration (see Figure 3, c). A similar $A_{\lambda}$ - $t$ curve to Figure 3 , c was also found when a catechin- $\mathrm{MgCl}_{2}$-Tris buffer solution was deaerated with argon (not shown). It also demonstrates that catechin protecting histone protein complexes exist. It is worth pointing out that such complexes could not be detected previously in our laboratory by UV-VIS absorption spectroscopic titrations (see Feucht et al. [11]). However, the results presented here indicate that association between catechin and histone proteins can be detected indirectly by kinetic investigation of the catechin stability. This finding appears to be of utmost importance since catechin is widely distributed in plants and is, for example, a major flavanol component in microspore nuclei of Taxus [34]. Thus, catechin may be really protected against oxidation by histone proteins. Indeed, it was shown in a recent paper that oxidized brown, frost damaged catechins were found in the cytoplasm of Tsuga canadensis, whereas the nucleus itself showed intact catechins which stained blue as usual (see [11, Figure 1(i)]).

The blue stained chromosomes in the mitotic spreads (see Figures 1(a), 1(i), 1(j), 1(k)) may allow three interpretations of the role of flavanols in nuclei: (1) protection of DNA against oxidative damage, (2) regulation of the methylation pattern of the DNA (epigenetic code of DNA), (3) regulation of chromatin remodeling, and of transcription by interacting with histone proteins. The kinetic results of the histonecatechin investigations favour a direct link to the histone transcription machinery. There are some indications that the catechin-histone interactions depend on the biochemical modification state of the histone proteins which is described by the epigenetic histone code ([11]). Recent results show that peptide sections from histones whose amino acids were modified can protect catechin from oxidation depending on their epigenetic modification (publication in preparation). Thus, flavanols may have an indirect influence on the epigenetic code of DNA through varied interactions with histones. It would not be surprising if the RNA interference itself should be also influenced by the flavanol (flavonoid) histone interactions.

4.4. Final Remarks. Much of the research on polyphenol complexation with proteins has been done with oligomeric or polymeric flavanols (Haslam [38]). However, from recent results it can be deduced that monomeric flavanols such as catechin, epicatechin, and epigallocatechin, which are major nuclear flavanols in a few conifers studied by Feucht et al. [34] play a special role in transcriptional activities on the level of epigenetics.

Initial daughter cells deriving from stem cells of Arabidopsis divide longitudinally to produce, as proposed by (Cui and Benfey [39]), cell lineages and later on via asymmetric cell divisions also the root ground tissue (cortex and endodermis). All of these divisions are under the control of epigenetics. In line with this, the discovery that each cell of a distinct Taxus lineage shows a clearly synchronized nuclear 
flavanol expression confirms the epigenetically controlled tissue patterning as proposed by Cui and Benfey.

Flavanols seem not only to be of vital importance for the global genome integrity but also for the intrachromosomal expression of genes. The nucleus as the most important centre for cellular regulation is not simply a storage compartment for flavanols or other flavonoids. This study offers a new view of the role of nuclear flavanols; however, much more remains to be discovered about the underlying molecular mechanisms.

\section{Acknowledgment}

This work is dedicated to Prof. Hanns-Ludwig Schmidt on occasion of his 80th anniversary.

\section{References}

[1] S.-U. Kim, E.-I. Hwang, J.-Y. Nam, et al., "Inhibition of chitin synthase II by catechins from stem bark of Taxus cuspidata," Planta Medica, vol. 65, no. 1, pp. 97-98, 1999.

[2] J. Polster, H. Dithmar, and W. Feucht, "Are histones the targets for flavan-3-ols (catechins) in nuclei?" Biological Chemistry, vol. 384, no. 7, pp. 997-1006, 2003.

[3] W. Feucht, D. Treutter, and J. Polster, "Flavanol binding of nuclei from tree species," Plant Cell Reports, vol. 22, no. 6, pp. 430-436, 2004.

[4] J. Polster, H. Dithmar, R. Burgemeister, G. Friedemann, and W. Feucht, "Flavonoids in plant nuclei: detection by laser microdissection and pressure catapulting (LMPC), in vivo staining, and uv-visible spectroscopic titration," Physiologia Plantarum, vol. 128, no. 1, pp. 163-174, 2006.

[5] D. E. Saslowsky, U. Warek, and B. S. J. Winkel, "Nuclear localization of flavonoid enzymes in Arabidopsis," Journal of Biological Chemistry, vol. 280, no. 25, pp. 23735-23740, 2005.

[6] P. Hutzler, R. Fischbach, W. Heller, et al., "Tissue localization of phenolic compounds in plants by confocal laser scanning microscopy," Journal of Experimental Botany, vol. 49, no. 323, pp. 953-965, 1998.

[7] M. Saran, Ch. Michel, and W. Bors, "Radical functions in vivo: a critical review of current concepts and hypotheses," Zeitschrift für Naturforschung C, vol. 53, no. 3-4, pp. 210-227, 1998.

[8] Ch. H. Foyer and G. Noctor, "Oxidant and antioxidant signalling in plants: a re-evaluation of the concept of oxidative stress in a physiological context," Plant, Cell and Environment, vol. 28, no. 8, pp. 1056-1071, 2005.

[9] V. Fey, R. Wagner, K. Bräutigam, and T. Pfannschmidt, "Photosynthetic redox control of nuclear gene expression," Journal of Experimental Botany, vol. 56, no. 416, pp. 14911498, 2005.

[10] L. R. Ferguson, "Role of plant polyphenols in genomic stability," Mutation Research, vol. 475, no. 1-2, pp. 89-111, 2001.

[11] W. Feucht, H. Dithmar, and J. Polster, "Variation of the nuclear, subnuclear and chromosomal flavanol deposition in Hemlock and Rye," International Journal of Molecular Sciences, vol. 8, no. 7, pp. 635-650, 2007.

[12] R. F. Lyndon, Plant Development, Unwin Hayman, London, UK, 1990.

[13] D. Marenduzzo, I. Faro-Trindade, and P. R. Cook, "What are the molecular ties that maintain genomic loops?" Trends in Genetics, vol. 23, no. 3, pp. 126-133, 2007.
[14] M. Lenhard and T. Laux, "Stem cell homeostasis in the Arabidopsis shoot meristem is regulated by intercellular movement of CLAVATA 3 and its sequestration by CLAVATA 1 ," Development, vol. 130, no. 14, pp. 3163-3173, 2003.

[15] J. D. Mauseth, Plant Anatomy, Benjamin/Cummings, Menlo Park, Calif, USA, 1988.

[16] T. Matsuo, "Chemistry, metabolism and biological functions of fruit tannins and reactive compounds," in Recent Research Developments in Phytochemistry, vol. 2, pp. 269-285, 1998.

[17] D. J. Tremethick, "Higher-order structures of chromatin: the elusive 30 nm fiber," Cell, vol. 128, no. 4, pp. 651-654, 2007.

[18] R. Strick, P. L. Strissel, K. Gavrilov, and R. Levi-Setti, "Cationchromatin binding as shown by ion microscopy is essential for the structural integrity of chromosomes," Journal of Cell Biology, vol. 155, no. 6, pp. 899-910, 2001.

[19] O. Leyser and S. Day, Mechanisms in Plant Development, Blackwell, CRD Press, Oxford, UK, 2003.

[20] B. Veit, "Stem cell signalling networks in plants," Plant Molecular Biology, vol. 60, no. 6, pp. 793-810, 2006.

[21] M. B. Singh and P. L. Bhalla, "Plant stem cells carve their own niche," Trends in Plant Science, vol. 11, no. 5, pp. 241-246, 2006.

[22] D. Weigel and G. Jürgens, "Stem cells that make stems," Nature, vol. 415, no. 6873, pp. 751-754, 2002.

[23] U. Wredle, B. Walles, and I. Hakman, "DNA fragmentation and nuclear degradation during programmed cell death in the suspensor and endosperm of Vicia faba," International Journal of Plant Sciences, vol. 162, no. 5, pp. 1053-1063, 2001.

[24] A. H. L. A. N. Gunawardena, J. S. Greenwood, and N. G. Dengler, "Programmed cell death remodels lace plant leaf shape during development," Plant Cell, vol. 16, no. 1, pp. 60-73, 2004.

[25] M. Mazumdar and T. Misteli, "Chromokinesins: multitalented players in mitosis," Trends in Cell Biology, vol. 15, no. 7, pp. 349-355, 2005.

[26] T. Misteli, "Protein dynamics: implications for nuclear architecture and gene expression," Science, vol. 291, no. 5505, pp. 843-847, 2001.

[27] S. I. S. Grewal and D. Moazed, "Heterochromatin and epigenetic control of gene expression," Science, vol. 301, no. 5634, pp. 798-802, 2003.

[28] S. M. Gasser, "Nuclear architecture: visualizing chromatin dynamics in interphase nuclei," Science, vol. 296, no. 5572, pp. 1412-1416, 2002.

[29] A. Lux-Endrich, D. Treutter, and W. Feucht, "Influence of nutrients and carbohydrate supply on the phenol composition of apple shoot cultures," Plant Cell, Tissue and Organ Culture, vol. 60 , no. 1, pp. 15-21, 2000.

[30] F. Rolland, E. Baena-Gonzalez, and J. Sheen, "Sugar sensing and signaling in plants: conserved and novel mechanisms," Annual Review of Plant Biology, vol. 57, pp. 675-709, 2006.

[31] T. Kouzarides, "Chromatin modifications and their function," Cell, vol. 128, no. 4, pp. 693-705, 2007.

[32] J. Fuchs, D. Demidov, A. Houben, and I. Schubert, "Chromosomal histone modification patterns-from conservation to diversity," Trends in Plant Science, vol. 11, no. 4, pp. 199-208, 2006.

[33] T.-F. Hsieh and R. L. Fischer, "Biology of chromatin dynamics," Annual Review of Plant Biology, vol. 56, pp. 327-351, 2005.

[34] W. Feucht, D. Treutter, H. Dithmar, and J. Polster, "Microspore development of three coniferous species: affinity of nuclei for flavonoids," Tree Physiology, vol. 28, no. 12, pp. 1783-1791, 2008. 
[35] M. Böhl, S. Tietze, A. Sokoll, et al., "Flavonoids affect actin functions in cytoplasm and nucleus," Biophysical Journal, vol. 93, no. 8, pp. 2767-2780, 2007.

[36] A. Sharma and S. Sen, Chromosome Botany, Science, Enfield, NH, USA, 2002.

[37] M. Jiménez-Atiénzar, J. Cabanes, F. Gandía-Herrero, and F. García-Carmona, "Kinetic analysis of catechin oxidation by polyphenol oxidase at neutral $\mathrm{pH}$," Biochemical and Biophysical Research Communications, vol. 319, no. 3, pp. 902-910, 2004.

[38] E. Haslam, Practical Polyphenolics. From Structure to Molecular Recognition and Physiological Action, Cambridge University Press, Cambridge, UK, 1998.

[39] H. Cui and P. N. Benfey, "Interplay between SCARECROW, GA and LIKE HETEROCHROMATIN PROTEIN 1 in ground tissue patterning in the Arabidopsis root," Plant Journal, vol. 58, no. 6, pp. 1016-1027, 2009. 

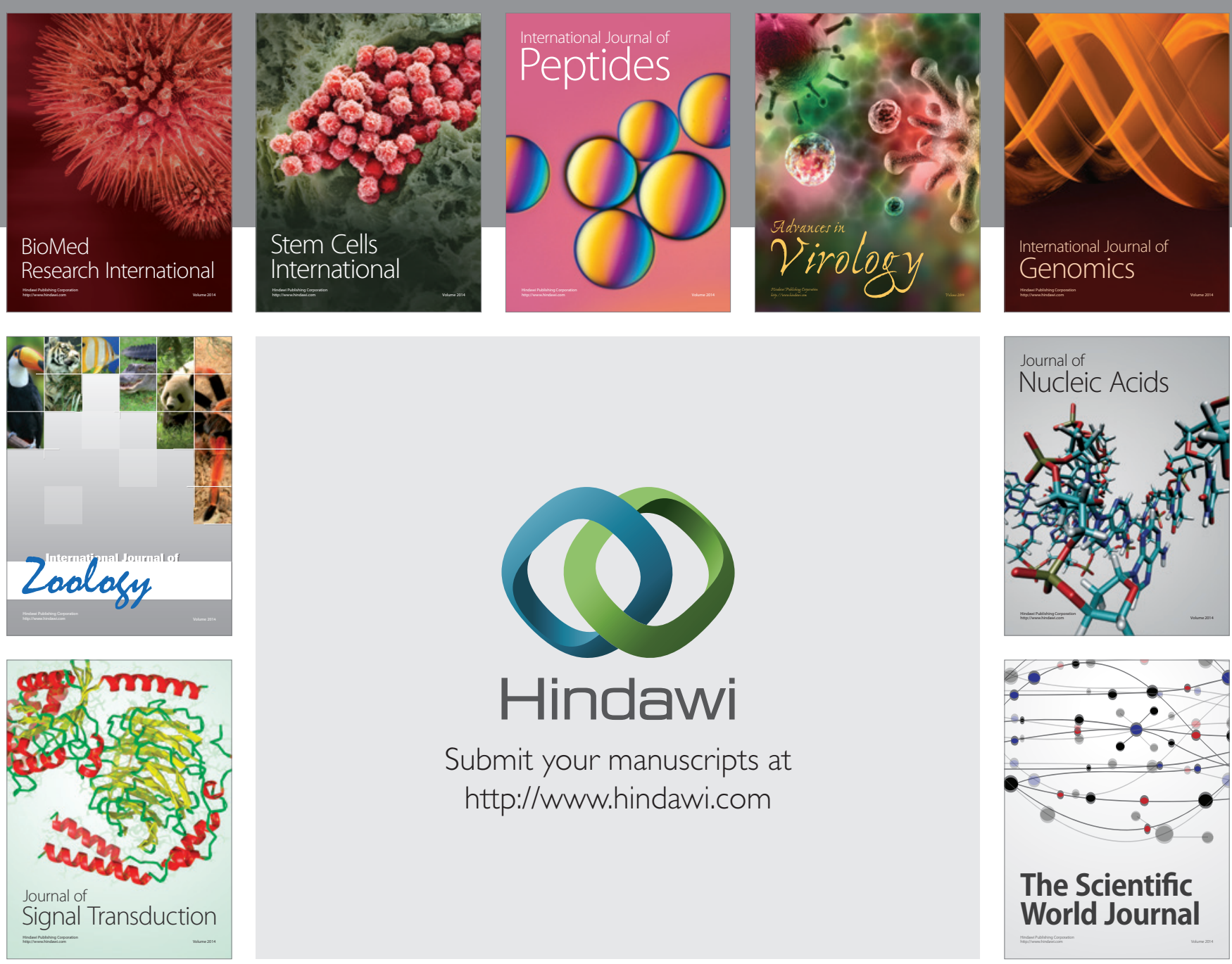

Submit your manuscripts at

http://www.hindawi.com
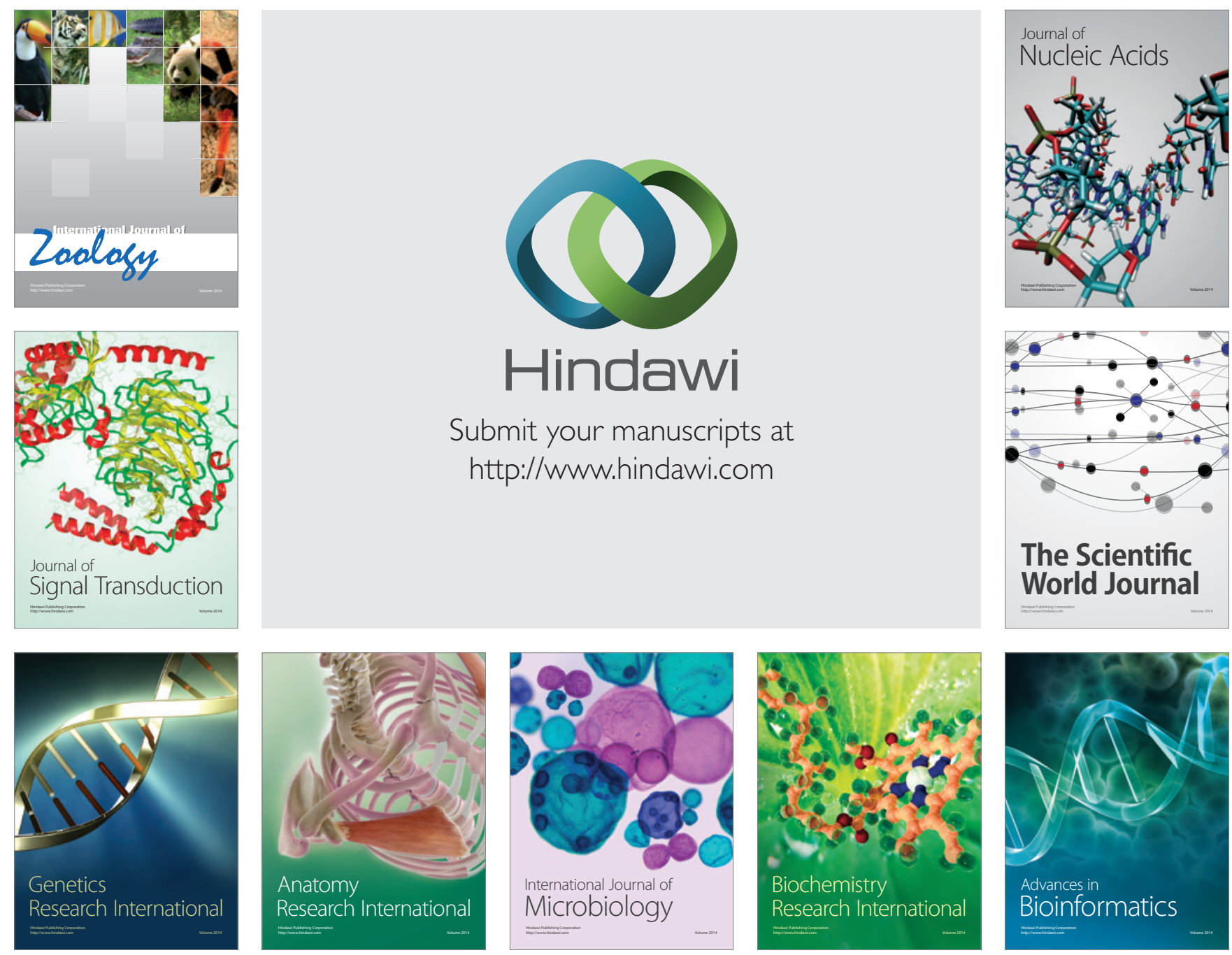

The Scientific World Journal
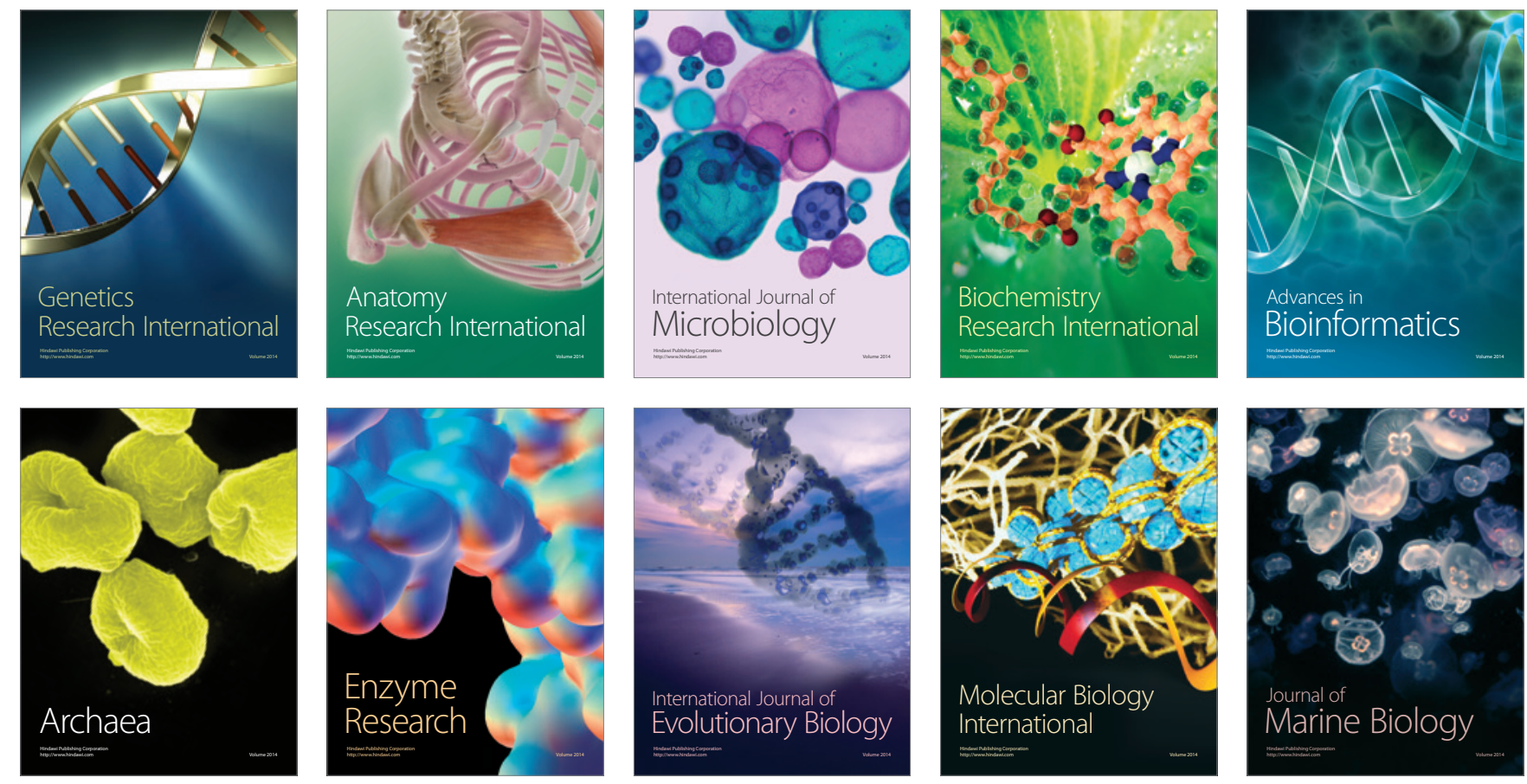